\title{
Kolonoskopi hazırlığı için polietilen glikol, sodyum fosfat ve sennosid kullanımının karşılaştırılması
}

\section{Mustafa KAPLAN}

Ahi Evran Üniversitesi Eğitim ve Araștırma Hastanesi, Gastroenteroloji Endoskopi Ünitesi, Kırșehir

\begin{abstract}
Giriş ve Amaç: Bu çalışmada kolonoskopi hazırlı̆̆ı için kullanılan polietilen glikol (PEG), sodyum fosfat ve sennosidin etkinlikleri, çekuma ulaşma oranlanı ve yan etkileri karşılaştırılmıştır. Gereç ve Yöntem: Bu çalışma Temmuz 2017-Mart 2018 tarihleri arasinda kolonoskopi yapılan hastalarnn kayıtlarn retrospektif incelenerek yapılmıştır. Hastalar; polietilen glikol, sodyum fosfat ve sennosid olarak 3 gruba bölünmüștür. Diyet uyumsuzluğu olan, ilaçların $\% 75$ ten azını içen, renal yetmezlik, intestinal obstrüksiyon, aktif enfeksiyon ve aktif kanaması olan hastalar çalışmadan dışlanmıştır. Kolon temizliği mükemmel, iyi, orta ve kötü olmak üzere 4 grupta değerlendirilmiştir. Bulgular: Araştırma popülasyonu 129 kadın (\%48) ve 140 erkek (\%52) erkek hasta olmak üzere 269 kişiden oluştu. Hastaların ortalama yaşı 55 yıldı. Tüm hastalar incelendiğinde mükemmel temizlik oranı \%38, iyi temizlik oran $\% 17$, orta temizlik oranı \%26 ve kötü temizlik oranı \%19 olarak bulundu. Sennosid grubunda yeterli temizlik oranı $\% 52$, sodyum fosfat grubunda $\% 50$ ve polietilen glikol grubunda \%66 olarak bulundu. Çalışmada 242 hastada çekuma ulaşıldı (\%90). Çekuma ulaşma oranı polietilen glikol grubunda $\% 100$ iken sennosid grubunda \%87 ve sodyum fosfat grubunda \%85 olarak bulunmuştur. Hastalarda en sık görülen yan etkiler ise bulantı/kusma (\%12) ve karın ağrısı idi (\%9). Sonuç: Polietilen glikol ile kolonoskopi hazırlığ sennosid ve sodyum fosfat ile hazırlığa göre daha efektif bir yöntemdir.
\end{abstract}

Anahtar kelimeler: Polietilen glikol, sodyum fosfat, sennosid, PEG
Background and aims: In this study, we compared polyethylene glycol, sodium phosphate and sennosid in terms of efficiency, cecal intubation rate, and side effects in colonoscopy preparation. Materials and Methods: This was a retrospective study where we assessed the medical records of patients undergoing colonoscopy between July 2017 and March 2018. The patients were divided into 3 groups: polyethylene glycol, sodium phosphate, and sennoside group. We excluded from the study patients with dietary restrictions, renal insufficiency, intestinal obstruction, active infection, active bleeding, and those who took fewer than $75 \%$ of their medications. Bowel preparation was rated as excellent, good, moderate, or poor. Results: The study population consisted of 269 patients, 129 female (48\%) and 140 male (52\%). The average age of the patients was 55 years. When all the patients were examined, an excellent cleaning rate was found in 38\% of the patients, a good cleaning rate was found in $17 \%$ of the patients, a moderate cleaning rate was found in $26 \%$ of the patients, and a poor cleaning rate was found in $19 \%$ of the patients. An adequate cleaning rate was found in $52 \%$ of the patients in the sennoside group, in $50 \%$ of the patients in the sodium phosphate group, and in $66 \%$ of the patients in the polyethylene glycol group. In this study, the total cecal intubation rate was $90 \%$. The cecal intubation rate was $100 \%$ in the polyethylene glycol group, $87 \%$ in the sennoside group, and $85 \%$ in the sodium phosphate group. The most common side effects in patients were nausea/vomiting (12\%) and abdominal pain (9\%). Conclusion: Colonoscopy preparation with polyethylene glycol is a method more effective than preparation with sennoside and sodium phosphate.

Key words: Polyethylene glycol, sodium phosphate, sennoside, PEG

olması nedeniyle böbrek yetmezliği hastalarında dikkatli kullanılması gereken bir laksatif grubudur (6). Polietilen glikol (PEG) ise 1980'lerden itibaren kullanılan, sindirilmeyen ve emilmeyen izotonik oral bir solüsyondur (7). Genellikle yüksek hacimle alınması ve tadının kötü olması en önemli dezavantajıdır. Sennosidler ise intestinal motiliteyi stimule eden ve epitelyal su elektrolit transportunu etkileyen laksatiflerdir (8). Özellikle yurtdışında yapılmış çalışmalarda sennosidin tek başına barsak temizliğinde kullanımı kısıtlıdır ancak ülkemizde sıklıkla kullanılmaktadır. Bu ilaçların etkinliği ile ilgili yapılmış çalışmalarda değişik temizlik oranları bulunmuştur, ancak ülkemizde yapılan çalışmaların çoğunda bu üç ilaç ikili olarak kıyaslanmaktadır $(9,10)$. Biz bu çalışmada kolonoskopi yapılan hastalarda bu ilaçların barsak temizliğinde etkinliğini, çekuma ulaşma oranlarını ve yan etkilerini araştırdık. 


\section{GEREÇ ve YÖNTEM}

Bu çalışma Temmuz 2017-Mart 2018 tarihleri arasında Kırşehir Ahi Evran Üniversitesi Hastanesi Endoskopi Ünitesi'nde kolonoskopi yapılan hastaların kayıtları retrospektif incelenerek yapılmıştır. Tam kolonoskopi yapılması amacıyla kolonoskopiye sevkedilen ve dışlanma kriterlerini karşılamayan tüm hastalar çalışmaya alınmıştır.

Hastaların diyet uyumları, ilaç kullanım durumları ve görülen yan etkiler hasta dosyalarından kaydedilmiştir. Kolonoskopi öncesi 3 günlük berrak diyet uygulanmayan işlem günü rektal yoldan iki adet lavman (BT enema $210 \mathrm{~mL}$, Yenişehir Lab., Ankara, Türkiye) kullanmayan hastalar çalışmadan dışlanmıştır. Hastanın ilacının en az dörtte üçünü bitirmiş olması verilen barsak hazırlığına uyum olarak tanımlanmıştır. Diyetine ve barsak hazırlığına uymayan; renal yetmezlik, semptomatik konjestif kalp yetmezliği, intestinal obstrüksiyonu, aktif kolonik inflamasyon veya kanaması olanlar ve kullanılan ilaçlara karşı alerjisi olan hastalar çalışmadan dışlanmıştır.

\section{Hasta Grupları}

Sodyum fosfat grubu: Hastalara kolonoskopiden 1 gün önce, saat 08 'de ve saat 18 'de $45 \mathrm{ml}+45 \mathrm{ml}$ olmak üzere toplam $90 \mathrm{ml}$ sodyum fosfat solüsyonu (Fleet Fosfo-Soda; Kozmed, Türkiye) toplamda 2 litre suyla beraber içirildi.

Sennosid grubu: Hastalara kolonoskopiden 1 gün önce, saat 18'de toplam 600 ml (1.2 gr) Sennosid A + B kalsiyum içeren 4 adet solüsyon ( X-M 150 ml Diet Solüsyon, Yenişehir Lab., Türkiye) 2 litrelik suya karıştırılıp her 15 dakikada $200 \mathrm{ml}$ içirildi.

PEG grubu: 4 litre suya PEG-3350 içeren Golytely (Braintree Laboratories, Inc, Braintree, MA ) karıştırılarak solüsyonlar hazırlandı ve hastalara uygulamadan önceki akşam saat 18'den itibaren her 10 dakikada bir 250 mililitre içirildi.

Hastaların kolon temizliği sınıflaması Amerikan Gastroenteroloji Derneği'nin barsak temizlik skalası göz ününe alınarak dört evrede değerlendirilmiştir (Tablol). Mükemmel ve iyi temizlik yeterli temizlik olarak kabul edilirken orta ve kötü temizlik yetersiz temizlenme olarak kabul edilmiştir.

Isslemlerde Fujinon EC-590WL4 kolonoskop (Fujinon Inc, Tokyo, Japonya) kullanılmıştır. Kolonoskopi esnasında has- talar monitörize edilerek; kan basınçları, kalp atım sayısı ve periferik oksijen satürasyonları kontrol altında tutulmuştur. Bütün hastalara işlem öncesi olası komplikasyonlar hakkında bilgi verilerek hastaların onamları alınmıştır. Ayrıca çalışma için yerel etik kurul onayı alınmıştır.

\section{BULGULAR}

Araştırma popülasyonu 129 kadın (\%48) ve 140 erkek (\%52) erkek hasta olmak üzere 269 kişiden oluştu. Hastaların ortalama yaşı 55 yıldı. Sennosid grubu 126 hastadan (\%47), sodyum fosfat grubu 75 hastadan (\%28) ve PEG grubu 68 hastadan (\%25) oluştu. Tüm hastalar incelendiğinde mükemmel temizlik oranı \%38, iyi temizlik oranı \%17, orta temizlik oranı \%26 ve kötü temizlik oranı \% 19 olarak bulundu. En sık kolonoskopik bulgular normal kolonoskopi (\%35) ve kolon polibi (\%26) idi. Hastaların tolerans durumu incelendiğinde en sık görülen yan etkiler bulantı/kusma (\%12) ve karın ağrısı (\%9) idi. Yan etkiler gruplar arasında farklılık göstermemiştir. Hastaların demografik ve klinik özellikleri Tablo 2'de verilmiştir.

Hasta gruplarının barsak temizlik oranları Tablo 3'te verilmiştir. Sennosid grubunda yeterli temizlik oranı \%52, sodyum fosfat grubunda \%50 ve PEG grubunda \%66 olarak bulunmuştur. 242 hastada çekuma ulaşılmıştır (\%90). Çekuma ulaşma oranı PEG grubunda \%100 iken sennosid grubunda $\% 87$ ve sodyum fosfat grubunda \%85 olarak bulunmuştur (Şekil 1).

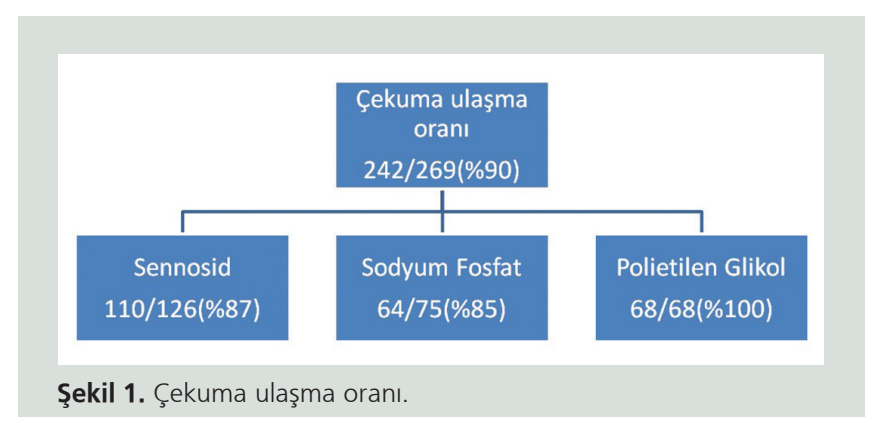

\section{TARTIŞMA}

İyi bir barsak temizliği kolonoskopi işleminin en önemli basamağıdır. Optimal kolon temizliği çekum intubasyonu ve neoplastik lezyonların saptanması oranını arttırırken işlem

\section{Tablo 1. Kolon temizliği sınıflaması}

\begin{tabular}{ll} 
Mükemmel & Tamamen temiz veya kolayca aspire edilebilen ve kolonun \%10'dan azını tutan sıvı \\
\hline İyi & Kolay aspire edilen fakat \%10'dan fazla sıvı \\
\hline Orta & Yarı katı gayta - \%10'dan az ancak kolonun \%75'ten fazlası incelebiliyor \\
Kötü & Aspire etmek ve yıkamakla gitmeyen katı gayta - \%10'dan fazla ve \% 75 'ten az mukoza gözlenebiliyor
\end{tabular}


Tablo 2. Demografik ve klinik özellikler

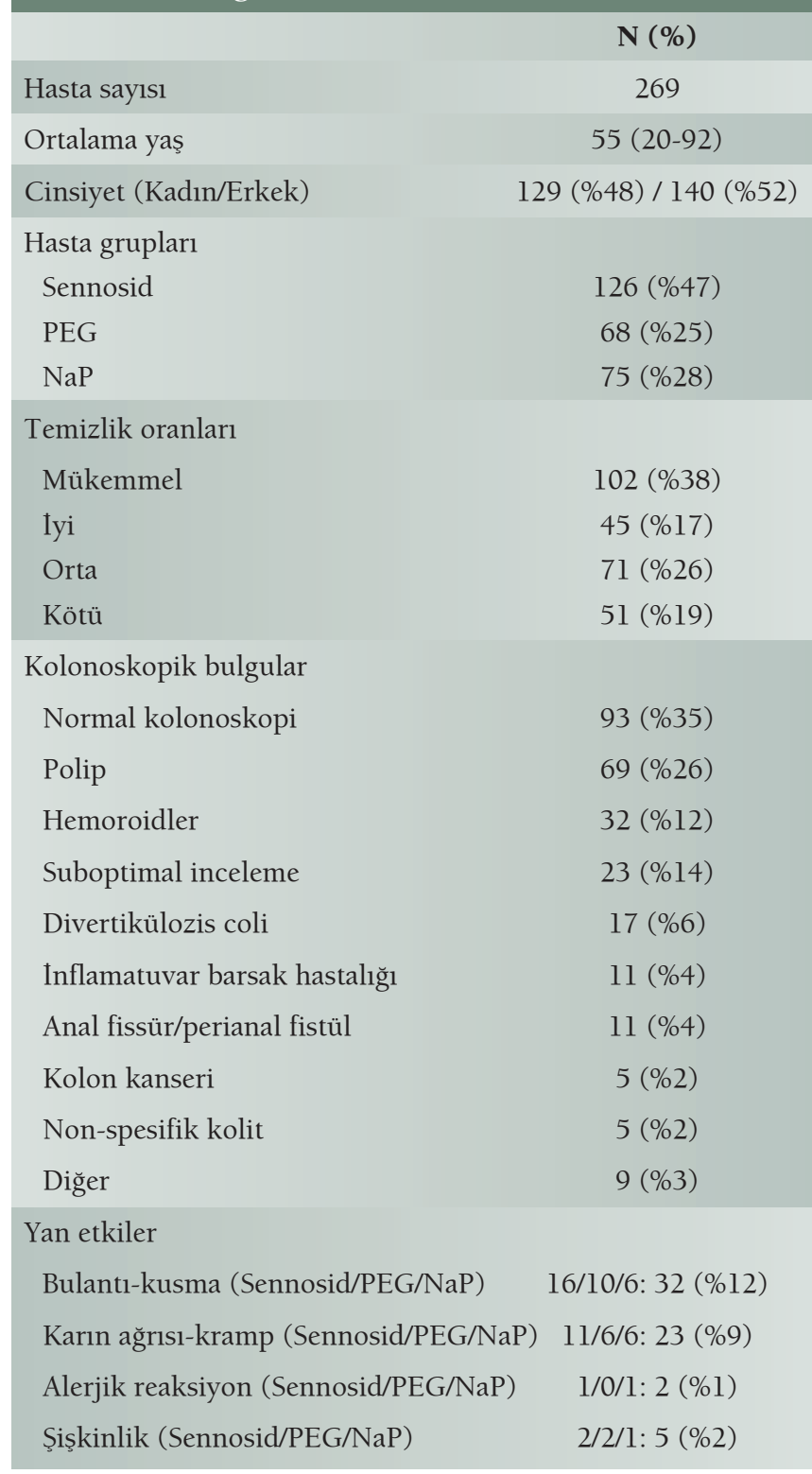

PEG: Polietilen glikol, NaP: Sodyum fosfat.

süresini ve işleme bağlı komplikasyonları azaltmaktadır. Bu çalışmada kolonoskopi hazırlığında PEG kullanımının hem barsak temizlik oranında hem de çekuma ulaşma oranında sodyum fosfat ve sennoside üstün olduğu gösterilmiştir.

Bu çalışma ülkemizde bu üç ilacı kıyaslayan ikinci çalışma olup daha önce Bektaş ve ark. yaptığı çalışmada bu üç ilacın etkinliği ve güvenilirliği benzer bulunmuştur (8). Bu çalışma- da PEG ve sodyum fosfat grubunda optimal temizlik oranları \%50 civarı bulunurken sennosid grubunda \%63 olarak bulunmuştur. Bizim çalışmamızda ise sennosid ve sodyum fosfat grubunda bu çalışmaya benzer şekilde optimal temizlik oranı \%50 civarında bulunurken PEG grubunda optimal temizlik oranı \%66 olarak bulunmuştur. Bu çalışmada ucuz olması ve PEG'e göre daha düşük volümlü olup hastalar tarafindan tekrar incelemede tercih edilmesi nedeniyle sodyum fosfat kullanımı önerilmiştir. Bizim çalışmamızda ise PEG diğer iki ilaca göre hem yeterli temizlik oranında hem de çekum intübasyonunda üstün bulunmuştur.

PEG iyi bir tercih olmakla birlikte özellikle yüksek volüm ile alınması bazı sıkıntılara yol açabilmektedir. Ancak bizim çalışmamızda buna bağlı yan etkiler görülmemiştir. Bunun sebebi ise çalışmaya ciddi kalp yetmezliği ve böbrek yetmezliği olan hastaların alınmamıs olmasıdır. Ancak literatür taramamızda PEG ile yapılan çalışmaların neredeyse tamamında bu dışlanma kriterlerinin olduğunu görmekteyiz. Fazla volüm alımı hastalarda daha çok abdominal distansiyon ve şişkinlik gibi yan etkilere sebep olmakla birlikte bizim çalışmamızda bu yan etkiler nerdeyse hiç görülmemiştir. Bu yan etkileri ortadan kaldırmak için daha az sıvı alımı ile PEG kullanılan çalışmalarda ise yeterli temizlik sağlanamamıştır (11).

Ülkemizdeki geri ödeme koşulları nedeniyle polietilen glikolun ödenmediği düşünüldüğünde bu çalışmada diğer sık kullanılan iki ilacın kıyaslanması da önem arz etmektedir. Bizim çalışmamızda bu iki ilacın etkinlik ve çekuma ulaşma bakımından benzer olduğu bulunmuştur. Literatür taramamızda sodyum fosfatın kolon temizliği için etkili ve ucuz bir ilaç olduğu belirtilmektedir (12). Sennosid ise ülkemizde çok sık kullanılmakla birlikte yurtdışında tek başına kullanımı ile ilgili yayın sayısı kısıtlı veya çok eski tarihlidir $(13,14)$. Yeni yapılan çalışmalarda sennosidin tek başına kullanılmasından ziyade PEG ve sodyum fosfata ilave olarak verilebileceği belirtilmektedir (15).

Daha önce yurtdışında yapılmış çalışmalarda \%90'ların üzerinde optimal temizlik oranları bulunurken bizim çalışmamızda bu oranının \%50-60'larda olduğu görülmektedir. Bu sonuçlar da diyete ve ilaç kullanımına uyduğunu söyleyen hastaların aslında çok fazla uyum göstermediğini düşündürmektedir. Bu nedenle hastaların etkin ilaç kullanımı ve diyet konusunda daha ayrıntılı bilgilendirmeye ihtiyaç olduğunu düşünüyoruz.

Tablo 3. Temizlik oranları

$\begin{array}{lccccc} & \text { Mükemmel } & \text { İyi } & \text { Orta } & \text { Kötü } & \text { Toplam 269 Hasta } \\ \text { Sennosid } & 46(\% 36) & 20(\% 16) & 32(\% 26) & 28(\% 22) & 126 \\ \text { Polietilen glikol } & 30(\% 46) & 14(\% 20) & 21(\% 30) & 3(\% 4) & 68 \\ \text { Sodyum fosfat } & 26(\% 35) & 11(\% 15) & 18(\% 24) & 20(\% 26) & 75\end{array}$


Çalışmamızda çekum intubasyon oranı \%90 olarak bulunmuştur. Daha önce yapılmış çalışmalarda \%50-\%96 arasında çekuma ulaşma oranları bildirilmektedir $(16,17)$. Böyle çok farklı sonuçların çıkması ise tamamen yapılan çalıșmaların metodolojisi ve dışlanma kriterleri ile alakalıdır. Calışmamızda çekum intübasyon oranında PEG'in diğer iki ilaca belirgin bir üstünlüğü saptanmıştır. Her ne kadar PEG grubunda optimal temiz olmayan hastalar bulunsa da bu hastaların tamamında çekuma ulaşılması en azından majör patoloji ekartasyonu açısından önem arz etmektedir. Diğer iki ilaçta yaklaşık \%10-12 hastada kirlilik nedeniyle çekuma hiç ulaşılamaması önemli majör patolojilerin atlanmasına sebep olabilmektedir.

Çalışmamızda kullanılan ilaçlara bağlı çok fazla yan etki görülmemiş ve yan etkiler gruplar arasında farklllık göstermemiştir. Çalışmamızda bulantı/kusma \% 12 oranına görülürken karın ağrısı \%9 hastada görülmüştür. Daha önceki yapılan çalışmalarda en sık görülen yan etkiler bizim çalışmamıza benzer olarak bulantı, kusma ve karın ağrısı iken bu yan etkilere ait \%10-55 arasında değișen oranlar bildirilmiștir $(8,18)$. Bu farklılı̆̆ı en önemli sebebi ise bizim çalışmamızın dışlanma

\section{KAYNAKLAR}

1. Harrison's Principles of Internal Medicine 16th Edition 2005;1858-9.

2. Memik F, Dolar E. Karaciğer sirozu. Tabak F, editör. Klinik Gastroenteroloji. I. Baskı, Istanbul; Nobel ve Güneş Tıp Kitapevleri. 2005;626-33.

3. Tabak F, Yurdaydın C, Kaymakoğlu S, et al; Guidelines Study Group VH. Diagnosis, management and treatment of hepatitis B virus infection: Turkey 2017 Clinical Practice Guidelines. Turk J Gastroentero 2017;28(Suppl 2):73-83.

4. Idilman R, Baykam N, Kaymakoğlu S, et al; Guidelines Study Group VH Turkey 2017 Clinical Practice Guidelines on recommendations for screening diagnosing and managing hepatitis C virus. Turk J Gastroenterol 2017 Dec;28(Suppl 2):90-93

5. Ökten A, Mungan Z, Çakaloğlu Y. Karaciğer sirozu: Gastroenterohepatoloji. Nobel Tip Kitapevi 2001;449-50.

6. Ökten A. Türkiye'de karaciğer sirozunun etiyolojisi. Hepatolojide Güncel Gelişmeler Sempozyumu Kitabı,1998; 67.

7. Quer J, Esteban J. Epidemiology. In: Thomas HC, Lemon S, Zuckerman AJ (eds). Viral hepatitis. Massachusetts, USA. Third Edition. Blackwell Publishing, 2005;407-25.

8. Bravo AA, Sheth SG, Chopra S. Liver biopsy. N Engl J Med 2001;344:495500 .

9. Sahin M, Karayakar F, Erdogan KE, et al. Liver tissue trace element levels in HepB patients and the relationship of these elements with histological injury in the liver and with clinical parameters. J Trace Elem Med Biol 2018:45:70-77.

10. Dienstag JL. The role of liver biopsy in chronic hepatitis C. Hepatology 2002;36(5 Suppl 1):S152-60

11. Bedossa P, Poynard T. An algorithm fort he grading of activity in chronic hepatitis C. The METAVIR Cooperative Study Group. Hepatology 1996;24:289-93

12. Silva AM, Matias CN, Nunes CL, et al. Lack of agreement of in vivo raw bioimpedance measurements obtained from two single and multi-frequency bioelectrical impedance devices. Eur J Clin Nutr 2018 Oct 22. [Epub ahead of print]

13. Ruiz-Vargas A, Ivorra A, Arkwright JW. Design, Construction and Validation of an Electrical Impedance Probe with Contact Force and Temperature Sensors Suitable for in-vivo Measurements. Sci Rep 2018;8:14818

14. Kushner RF. Bioelectrical impedance analysis: a review of principles and applications. J Am Coll Nutr 1992;11:199-209. kriterleridir. Daha önce yapılmış çalışmalarda diyet uyumu olmayan ve ilacı tam kullanmayan hastalar çalışmaya alınmıştır (19). Biz ise bu ilaçların esas olarak barsak temizliğindeki etkinliğini ve çekuma ulaşma oranını kıyasladığımız için ilaçları bulantı, kusma ve karın ağrısı gibi yan etkiler nedeniyle kullanamayan hastaları çalışmamıza almadık. Bu nedenle yan etkiler diğer çalışmalara göre daha düşük bulunmuştur.

Çalışmamızın en önemli kısıtlılı̆̆ı dışlanma kriterleri nedeniyle olası yan etkilerin tam olarak değerlendirilememesidir. Bu çalışmanın esas amacı ülkemizde kolon temizliği için en sık kullanılan üç ilacın temizlikteki etkinliğini araştırmak olduğu için yan etkiler ikinci planda kalmıştır. Diğer bir önemli kısıtllı̆̆ı̆ımı ise daha önce yapılan çalışmalarda anketlerde uygulanan ilaç memnuniyeti ve tekrar kullanıp kullanmak istemediğine dair bilginin bizim çalıșmamızda olmamasıdır.

Sonuç olarak PEG ile kolonoskopi hazırllğı sennosid ve sodyum fosfat grubuna göre daha etkin ve efektif bir yöntemdir. Bu üç ilacın tek başına ve kombine kullanımını araştıran randomize kontrollü çalışmalar yapılmasına ihtiyaç duyulmaktadır.

15. Baumgartner RN, Chumlea WC, Roche AF. Impedance for body composition. Exerc Sport Sci Rev 1990;18:193-224.

16. Houtkopper LB, Lohman TG, Going SB, Howell WH. Why bioelectrical impedance analysis should be used for estimating adiposity. Am J Clin Nutr 1996;64(3 Suppl):436S-448S.

17. Köksal 1, Yılmaz G, Parlak M, et al; Study Group TCHC. Diagnostic value of combined serum biomarkers for the evaluation of liver fibrosis in chronic hepatitis $\mathrm{C}$ infection: A multicenter, non interventional, observational study. Turk J Gastroenterol 2018;29:464-472.

18. Kushner RF, Guidivaka R, Scholler DA. Clinical characteristics influencig bioelectrical impedance analysis measurements. Am J Clin Nutr 1996;64(3 Suppl):423S-427S

19. Kravetz D, Arderiu MT, Bosch J, et al. Increased plasma volume in two models of portal hypertension in the rat: Cirrhosis of the liver and partial portal vein ligation. Rev Esp Fisiol 1987;43:179-83.

20. Guglielmi FW, Contento F, Laddaga L, et al. Bioelectric impedance analysis: experience with male patients with cirrhosis. Hepatology 1991;13:892-5.

21. Cabré E, de León R, Planas R, et al. Reliability of bioelectric impedance analysis as a method of nutritional monitoring in cirrhosis with ascites. Gastroenterol Hepatol 1995;18:359-65.

22. Runyon BA, Montano AA, Akriviadis EA, et al. The serum ascites albumin gradient is superior to the exudates-transudate concept in the differential diagnosis of ascites. Ann Int Med 1992;117:215-20.

23. Kahraman A, Hilsenbeck J, Nyga M, et al. Bioelectrical impedance analysis in clinical practice: implications for hepatitis $C$ therapy BIA and hepatitis C. Virol J 2010;7:191.

24. Guida B, Laccetti R, Gerardi C, et al. Bioelectrical impedance analysis and agerelated differences of body composition in the elderly. Nutr Metab Cardiovasc Dis 2007;17:175-80.

25. Barbosa-Silva MC, Barros AJ, Wang J, et al. Bioelectrical impedance analysis: population reference values for phase angle by age and sex. Am J Clin Nutr 2005;82:49-52.

26. Selberg O, Selberg D. Norms and correlates of bioimpedance phase angle in healthy human subjects, hospitalized patients, and patients with liver cirrhosis. Eur J Appl Physiol 2002;86:509-16.

27. Pirlich M, Schutz T, Spachos T, et al. Bioelectrical impedance analysis is a useful bedside technique to assess malnutrition in cirrhotic patients with and without ascites. Hepatology 2000;32:1208-15. 